\section{MEMBRANES}

\section{Argument}

from our Molecular Biology Correspondent A system that has done service as an archetype for the structure of biological membranes is the retinal rod outer segment. A feature that especially commends it for such a role is that it contains only one protein in large quantity. After some early skirmishing the X-ray practitioners appeared to reach general agreement about the electron density profile across the bilayer, and more particularly in the conclusion that the electron densities, given the proportions of rhodopsin and phospholipid in the membrane, could not be made to add up for any model embodying protein totally submerged in the bilayer, or plating the surfaces, and were best compatible with globules floating, only partly immersed, in the membrane fluid.

Last year Dratz and his colleagues (Nature New Biology, 237, $99 ; 1972$ ) attempted to shatter this tranquil accord by arguments based on chemical labelling experiments in intact rod outer segment membranes compared with the isolated rhodopsin. In this they seem to have been wrecked on a reef that has accounted for many a good protein chemist in its time, and now familiar to most, namely that the reactivity of side chains in proteins is controlled by a variety of factors besides mere steric accessibility. The plan was to use a macroscopic labelling reagent, which would be unable to enter the bilayer, and could therefore modify only groups exposed to the aqueous exterior. The reagent in question was fluorescein isothiocyanate adsorbed on a colloidal particle, which was found to react abundantly with rhodopsin, free or in membranes that had been broken up with detergent or a phospholipase, but not in the intact or even sonicated membrane. From this they boldly inferred that the rhodopsin in situ must be totally buried within the bilayer.

Vanderkooi in this week's issue of Nature New Biology (242, 212 ; 1973) now points out that this will not wash. Besides the evidence of the phalanx of $\mathrm{X}$-ray crystallographers, he draws attention to the likely role of environmental factors in determining the reactivity of the reactive lysine, tyrosine and cysteine side chains of the protein. It is known that rhodopsin reacts in situ with aldehydes, and with thiol reagents: three of the latter, all polar iodoacetamide derivatives, react with one of the two reactive thiols of the protein. There is, moreover, the recent work of Blasie, which purports to demonstrate steric changes in the membrane within a $p H$ range in which only charged groups on the protein could change their ionization states.
In their rejoinder Dratz and Schwartz (ibid., 212) seem more concerned with repudiating Vanderkooi's arguments than defending their own position, which they seem in any case to have stealthily evacuated in the interim. The aldehydes, they say, can enter the lipid phase, and react with the protein side chains that they find there. As to the thiol reagents (work reported last year by $\mathrm{Wu}$ and Stryer) the results, they assert, prove nothing: two of the reagents have a sufficiently wide separation between the non-polar reactive centre and the polar carrier group that the reaction could occur under the bilayer surface; the third reagent, they believe, might actually be lipid-soluble. Blasie's evidence they counter by questioning whether he has correctly identified an $\mathrm{X}$-ray reflexion that he uses to measure the inter-protein spacing. They have also, they say, calculated Fourier syntheses for the various possible models for the membrane, and whereas some fit the observed electron density profiles in some regards, they fall short in others. This, of course, is not unfamiliar to the crystallographers who have been toiling in the field for some years, and who have recently stressed particularly the complications arising from the structural disorder that is thought to be present. Dratz and Schwartz then come to the point: work of their own and of two other groups, using specific labelling methods in results as yet only available as published abstracts, shows that part of the rhodopsin is indeed exposed to the aqueous medium: the view that the protein floats partly immersed in the bilayer therefore remains unassailed, and the earlier labelling results were, as one suspected, writ on water.

Also in Nature New Biology this week (ibid., 213) is a sequel by Phillips and Morrison to their earlier work on labelling of membrane proteins by a reagent too large to penetrate the bilayer. This is nothing less than a protein, lactoperoxidase, which catalyses the iodination of tyrosine residues. In the red cell, only two proteins are labelled from the outside by this means, one of them the principal glycoprotein, which bears surface receptors for such ligands as plant lectins. As with cells in tissue culture, limited exposure to trypsin results in increased agglutination in the presence of such species, and it has been variously argued that the trypsin treat ment leads to exposure of new binding sites, or to increased freedom of the receptor protein to form strongly binding clusters in the membrane. Phillips and Morrison now find that trypsin releases glycopeptides, including one that contains the tyrosines iodinated by lactoperoxidase. In spite of the removal of this reactive residue, the trypsintreated cells are able to incorporate ten times more label than the untreated, exclusively, moreover, in the same two proteins. These results can be most simply interpreted in terms of the obstruction of much of the surface protein by a fur of carbohydrate, which might well turn out to be a widespread structural feature in membranes.

\title{
ER Virus Superinfection of Human Lymphocytes
}

LiNES of human lymphoid cells which multiply indefinitely in culture have, irrespective of their origin, proved to contain Epstein-Barr (EB) virus DNA and $E B$ virus has been implicated in the aetiology of Burkitt's lymphoma and infectious mononucleosis. Cells of many of these lymphoid lines can be superinfected with EB virus even though they contain EB virus DNA.

In Nature New Biology next Wednesday (April 25) Adams and Klein report an analysis of the response to superinfection with EB virus of cells of eleven human lymphoid lines, six derived from Burkitt lymphoma tissue and five derived from patients with infectious mono-

\section{Correction}

THE article by Riddle and Carbon referred to in a note, "Frameshift Suppressor Transfer RNA", in last week's issue (Nature, 242, 436; 1973), will be published in Nature New Biology for April 25 and not April 18 as stated. nucleosis, a patient with leukaemia and from healthy persons. Their findings lead them to the interesting conclusion that either lymphocytes from Burkitt lymphoma tissue differ in type from non-Burkitt lymphocytes, or different subtypes of EB virus are present in the Burkitt and non-Burkitt cells, or the mechanism of transformation of the two classes of cells differs.

Cells of all the lines studied adsorbed EB virus, and one particular stock of this virus proved to be unusually active in inducing viral early antigen. Adams and Klein therefore used this stock to measure the dose response relationship of the Burkitt and non-Burkitt cells. Cells of eight of the eleven lines fell into one of two classes when their dose response curve for the induction of viral early antigen was measured, the nonBurkitt cells having a linear dose response whereas the Burkitt cells had something approaching an exponential dose response. Moreover, three lines, two Burkitt and one non-Burkitt, responded with the production of early antigen much more strongly than the other eight lines. 